Research Article

\title{
Experimental Research on Axial Compression of Reinforced Concrete Short Circular Columns Strengthened with Prestressed Semicircular Steel Plates
}

\author{
Zhenhua Ren, ${ }^{1}$ Yaqian Shen, ${ }^{1}$ Xiantao Zeng $\mathbb{D}^{1},{ }^{1}$ and Yuantian Sun $\mathbb{D}^{2}$ \\ ${ }^{1}$ Hunan Provincial Key Laboratory of Intelligent Disaster Prevention-Mitigation and Ecological Restoration in Civil Engineering, \\ Hunan Institute of Engineering, Hunan, Xiangtan 411104, China \\ ${ }^{2}$ School of Mines, Key Laboratory of Deep Coal Resource Mining, Ministry of Education of China, \\ China University of Mining and Technology, Xuzhou 221116, China
}

Correspondence should be addressed to Xiantao Zeng; xtzeng63@163.com

Received 7 September 2021; Accepted 1 November 2021; Published 23 November 2021

Academic Editor: Wenjie Ge

Copyright ( 12021 Zhenhua Ren et al. This is an open access article distributed under the Creative Commons Attribution License, which permits unrestricted use, distribution, and reproduction in any medium, provided the original work is properly cited.

According to the statistics of relevant departments, the total area of various existing buildings in China is at least 10 billion $\mathrm{m}^{2}$, of which about one-third of the houses have reached the design life and the safety reserve is insufficient. It is not economical to demolish these houses and rebuild them, and the benefits of new buildings are far less than those of extending the service life of old buildings through reinforcement. Therefore, reinforcement technology is increasingly indispensable. Currently varying methods for the prestressed reinforcement of concrete columns are developed, but they are generally not practical. Strengthening concrete columns with prestressed semicircular steel plate is a new prestressed strengthening technology. In this article, the experimental study on the axial compression of a reinforced concrete circular section short column strengthened with prestressed semicircular steel plate is carried out by combining experimental and numerical simulation methods, and the calculation formula of the bearing capacity of the reinforced short column is established by finite element analysis.

\section{Introduction}

The application of prestress reinforcement in a building structure improves the force performance of the original structure by enhancing crack resistance, structural carrying capacity, and durability [1-3]. Currently varying methods for the prestressed reinforcement of concrete columns are developed comprising prestressed rod, prestressed strip, and prestressed steel strand reinforcement methods [4-7]. However, the application of prestressed reinforcement technology in practical engineering is still in the preliminary stage. Zhang et al. [8] explored the anchorage-reinforced concrete column (similar to the clamp method) by the quasistatic test to find the circumferential prestressed steel strands and demonstrated good repair and improvement effect on the seismic performance of damaged columns. Prestressed steel strand has the advantages of convenient construction and short cycle and does not affect the use of the original structure during construction. It can also improve the bearing capacity, stiffness, and energy dissipation capacity of reinforced concrete columns. After reinforcement, the fire resistance, corrosion resistance, and aging resistance of the components are improved $[9,10]$. Ge et al. [11] studied the seismic behavior of concrete columns strengthened by prestressed steel strand tensioning and anchoring. The test results show that the yield load and ultimate load were improved, but the concrete of the protective layer of the original column exposed to the prestressed steel strand is in the three-dimensional stress state, and the exposed concrete is still in the two-dimensional stress state, which makes the mechanical state of the concrete column more complex, which brings complexity to the design calculation, and the prestress of the steel strand is limited. Sun et al. [12] found a prestressed steel plate hoop to 
reinforce bridge and effectively improve axial compression bearing capacity and deformation capacity of pier column. The axial compression performance tests of 16 reinforced columns and 2 contrast columns were carried out by Sun et al. [13] and Yong et al. [14]. The results show that the bearing capacity and deformation capacity of reinforced columns are improved under the conditions of constant spacing of steel strips, increasing or unchanged number of layers, and decreasing spacing. However, the column concrete between steel strips is exposed outside, which is not constrained by steel strips, leading to increased potential of early explosion $[8,15]$. From the above research status, can we find a prestressed reinforcement method? It can not only improve the deformation resistance and bearing capacity of reinforced concrete columns, but also ensure that the stress of new and old structural layers is synchronized, the original structure is not destroyed, and the implementation is convenient.

Therefore, the prestressed semicircular steel plate is firstly proposed as a feasible solution toward the increased demand as shown in Figure 1. The main novelty is that two prestressed semicircular steel plates are installed on the side of the required strengthened cylinder, and the circumferential prestress is applied to the two semicircular steel plates by tightening the bolts. The prestress can be adjusted by tightening the bolts, so as to improve the bearing capacity of concrete columns without damaging the original column, and to achieve the purpose of rapid repair and reinforcement of concrete columns. As a result, compared to traditional reinforcement methods such as increasing section method $[16,17]$, steel casing method $[18,19]$, and CFRP reinforcement method $[20,21]$, the advantage can be concluded as follows: (1) It does not increase the section of the column, nor add steel bars to the original column. (2) Its core concrete is in the active three-way stress state before the force. (3) The original concrete column has reinforcement according to the original bearing requirements. The reinforced concrete column is equivalent to the prestressed reinforced concrete-filled steel tube column, and its bearing capacity is higher than that of the concrete-filled steel tube column. (4) The prestress can be adjusted to ensure the force synchronization of the original structure and the reinforced structure, and there will be no echelon damage. (5) The reinforcement does not damage the structure of the original concrete column, nor does it reduce its bearing capacity. (6) It is not necessary to unload the original concrete column and does not affect the use of the structure. The reinforcement construction can be implemented online and can be carried immediately after reinforcement. The structure demonstrates promising potential in intelligence manufacture owning to its superior advantages especially in the $3 \mathrm{D}$ printing domain [22-24].

In this article, the experimental study on the axial compression of the reinforced concrete circular section short column strengthened with prestressed semicircular steel plate is carried out by combining experimental and numerical simulation methods, and the calculation formula of bearing capacity of the reinforced short column is established by finite element analysis. In order to study the axial
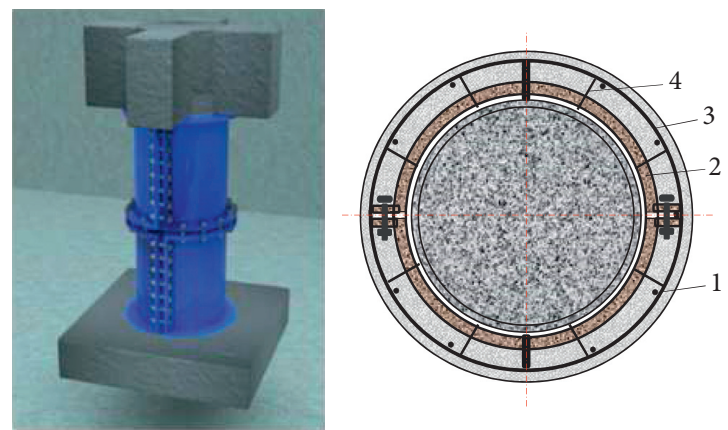

FIgURE 1: Schematic diagram of the reinforcement method. (1) Longitudinal bar; (2) semicircular steel plate; (3) stirrup; (4) radial structural bars.

bearing capacity of strengthened concrete columns, the axial compression tests of 20 concrete columns were completed, including 5 comparative columns and 15 concrete columns. All specimens were strengthened by steel casing with varying prestressing values. The test results show that the bearing capacity of the reinforced concrete column is greatly improved by prestressed steel casing, and the ultimate bearing capacity is increased by $72.1 \%-109.9 \%$. On the basis of the experimental study, the finite element models of the prestressed semicircular steel plate strengthened column were established by ABAQUS. The correctness of the finite element model is verified by the experimental results. Finally, the bearing capacity of the reinforced concrete column is analyzed theoretically, to propose the calculation formula for axial compression bearing capacity; compared with the experimental data, the theoretical calculation formula has outstanding accuracy, Through this test, it can provide experimental data for the eccentric compressive test, earthquake-resistant test, shear test, resistant explosion experiment, fatigue test, and stability test of the prestressed steel casing reinforcement method for strengthening the concrete column.

\section{Materials and Methods}

2.1. Materials and Specimen Design. The concrete in this test is C30. According to Chinese Standard Test Method (GB/ T50081-2016) [25], the same batch of concrete with the cylinder was selected for the compressive performance test of a concrete cube, and the average compressive strength of the concrete cube was $30.75 \mathrm{MPa}$.

As shown in Figure 2(a), 6C14HRB400E was selected as the longitudinal bar. According to the Steel Test Method for Reinforced Concrete (GB/T28900-2012) [26], the yield strength of the longitudinal bar was measured to be $541 \mathrm{MPa}$. The yield strength of the stirrup A6HPB300 is $332 \mathrm{MPa}$.

The test column is circular, $256 \mathrm{~mm}$ in diameter, and $1000 \mathrm{~mm}$ in height (Figure 2(b)). A total of 20 columns were designed in this experiment, of which 5 were the contrast columns, numbered RC-1 (the specific column numbers are $\mathrm{RC}-11$ to $\mathrm{RC}-15)$, and the remaining 15 were divided into three groups of different prestressed reinforced concrete columns, numbered RC-2-1-RC-2-3 (the specific column numbers of each group are RC-2-11 RC-2-15). 


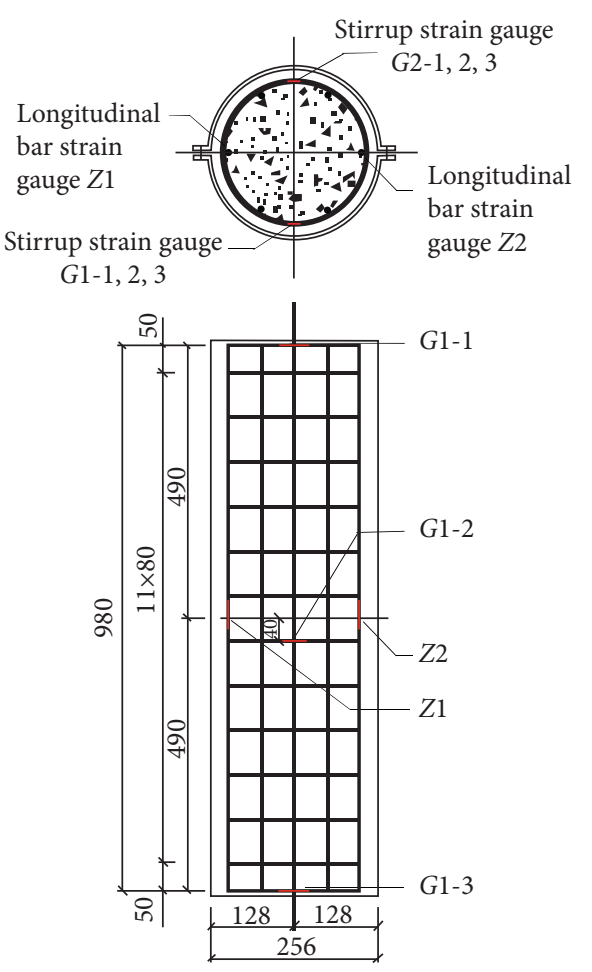

(a)

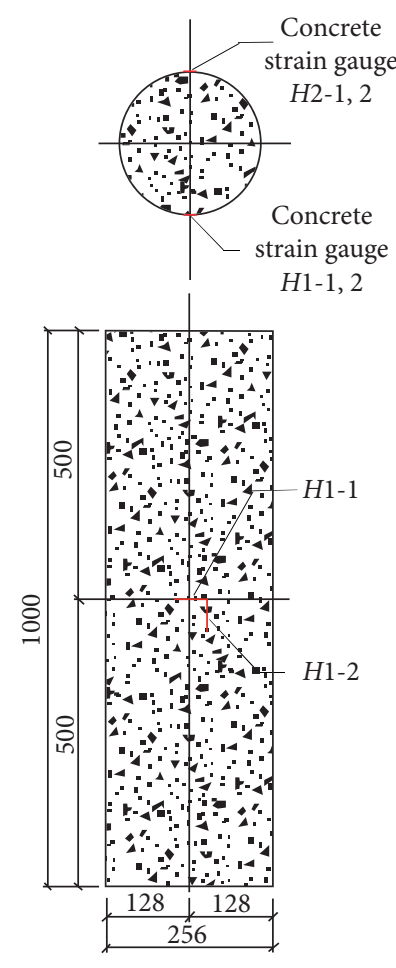

(b)

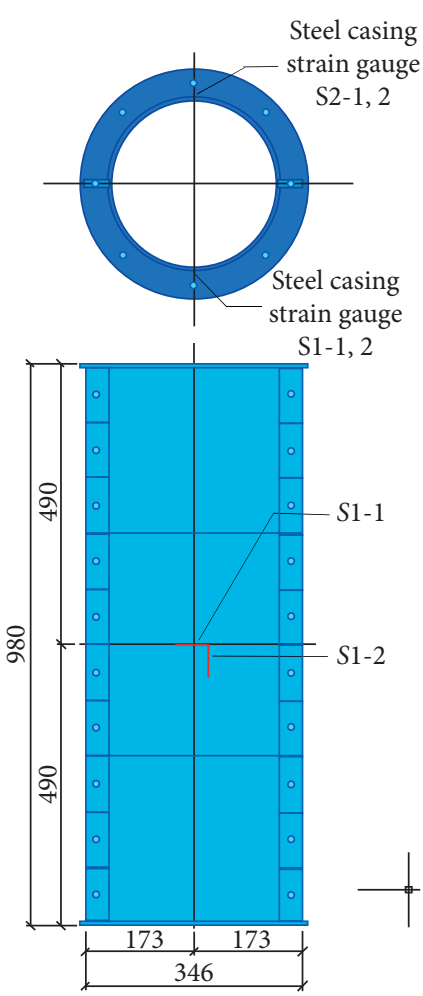

(c)

FIgUre 2: Details of specimens.

As shown in Figure 2(c), the inner diameter of the steel casing wall is $256 \mathrm{~mm}$, the length is $980 \mathrm{~mm}$, and the thickness of the steel plate is $5 \mathrm{~mm}$. In order to make the steel casing successfully impose circumferential prestress on the concrete cylinder, the two semicircular steel plates cannot be closed into a complete circle, and the two semicircular steel plates should leave $6 \mathrm{~mm}(256 \times \pi \times 0.01 \times 1.5=12 \mathrm{~mm}, 0.01$ is the ultimate tensile strain of steel, and 1.5 is the surplus coefficient) gaps in advance.

The nominal diameter was $12 \mathrm{~mm}$, and the stress crosssectional area of M12 bolt was $84.3 \mathrm{~mm}^{2}$.

In order to measure the internal stress and deformation of the steel bar, concrete, and steel casing, strain gauges are affixed at the specific position of the specimen, and the specific position of the strain gauge is shown in Figure 2.

2.2. Loading Program. In order to study the mechanical properties and reinforcement effect of concrete columns strengthened with steel casting (steel cylinder formed by closing two semicircular steel plates) under precompression stress, four groups of axial compression tests of strengthened columns were carried out:
(1) Contrast column test of the unreinforced original column.

(2) According to the prestress value, the test of the reinforced column can be divided into the following three categories:

(1) In Scheme 1, the prestress value is 0 , which means tightening the bolt gently with a common wrench so that the steel casing is just close to the surface of the concrete cylinder; therefore, reinforced columns are equivalent to reinforced concretefilled steel tubular columns.

(2) In Scheme 2, the confining pressure of the semicircular steel plate on the concrete column is equivalent to that of the unreinforced column stirrup on core concrete. As shown in Figure 3, $p=\sigma_{r}\left(p\right.$ is shown in Figure 3(c), and $\sigma_{r}$ is the confining pressure of steel casing on concrete columns); therefore, $\sigma_{3}=\sigma_{r}$ (Figure 3(c)).

Because the thickness of the semicircular steel plate is far less than the diameter of the concrete column, and the thickness of the steel plate is $t=5 \mathrm{~mm}$, the cross-sectional area of the steel tube wall is $A_{s 1}=4097.70 \mathrm{~mm}^{2}$. When the diameter of the 


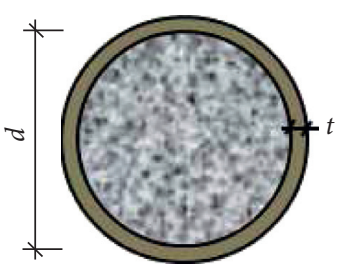

(a)

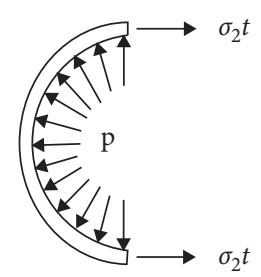

(b)

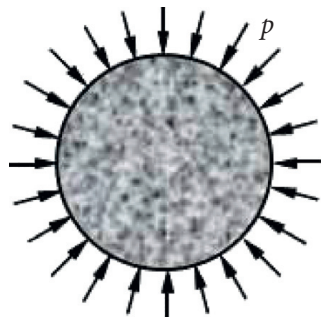

(c)

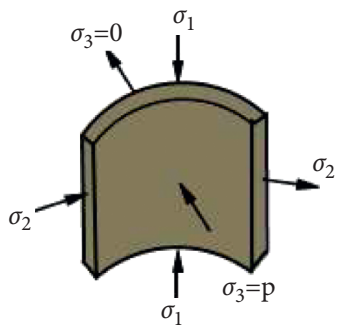

(d)

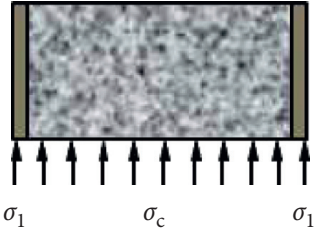

(e)

Figure 3: Stress diagram after reinforcement.

column is $d=256 \mathrm{~mm}$ and the thickness of the concrete cover is $25 \mathrm{~mm}$, the diameter of core concrete (stirrup spacing) is $194 \mathrm{~mm}$ and the area of core concrete is $A_{\text {cor }}=29544.26 \mathrm{~mm}^{2}$. The crosssectional area of concrete column $A=51445.76 \mathrm{~mm}^{2}$, and the stirrup conversion area is $A_{s s 0}=215.19 \mathrm{~mm}^{2}$. Therefore, the constraint stress $\left(\sigma_{r 1}\right)$ of stirrup on the core concrete column can be calculated by the following formula $[27,28]$ :

$\sigma_{r 1}=\frac{f_{y v} \cdot A_{s s 0}}{2 A_{c o r}}=\frac{270 \times 215.19}{2 \times 29544.26}=0.983 \frac{\mathrm{N}}{\mathrm{mm}^{2}}$,

where $f_{y v}$ is the design value of stirrup tensile strength, $f_{y v}=270 \mathrm{MPa}$. When the confining pressure of steel casing on the surface of the concrete column is equal to that of stirrup on core concrete before column reinforcement, there should be

$$
\sigma_{r}=\sigma_{r 1}
$$

At this time, the circumferential tensile stress in the steel casing plate can be obtained as follows:

$$
\sigma_{\theta}=2 \sigma_{r} \frac{A}{A_{\mathrm{s} 1}}=2 \times 0.983 \times \frac{51445.76}{4097.70}=24.68 \frac{\mathrm{N}}{\mathrm{mm}^{2}} \text {. }
$$

(3) In Scheme 3, the prestress value is equivalent to the prestress value required to make the bolt reach its tensile strength design value. At this time, the tensile force of the steel casing is larger than that of Scheme 2. The design value of the axial tensile connection bearing capacity of a single bolt is set as $N_{t}^{b}$ :

$$
N_{t}^{b}=A_{\mathrm{eff}} f_{t}^{b}=84.3 \times 400=33270 \mathrm{~N},
$$

where $A_{\text {eff }}$ is the stress section area of a single bolt, $A_{\text {eff }}=84.3 \mathrm{~mm}^{2} . f_{t}^{b}$ is the tensile design strength of the bolt, $f_{t}^{b}=400 \mathrm{MPa}$. In addition, the number of bolts per row is 10 :

$$
\sigma_{\theta}=\frac{N_{t}^{b} \times 10}{t \cdot l}=\frac{33270 \times 10}{5 \times 980}=67.90 \frac{\mathrm{N}}{\mathrm{mm}^{2}},
$$

where $t$ is the thickness of the steel casing plate, $t=5 \mathrm{~mm}$ and $l$ is the height of steel casing, $l=980 \mathrm{~mm}$. Therefore, the grouping scheme and the corresponding prestress values are listed in Table 1.

The loading method is full-section axial compression. The test is carried out on the microcomputer controlled electro-hydraulic servo press-shear testing machine. The strain of steel bars, steel casings, and concrete is measured by the static resistance strain gauge DH3818Y and dynamic signal acquisition and analysis system DHDAS. The cracks are observed with the naked eye of the magnifying glass and the flashlight. The testing machine is shown in Figure 4.

The test loading was carried out according to the Standard Test Method for Concrete Structures (GB/T501522012) [29]. After the reinforcement column is aligned, the preloading of $0.3 N_{u}$ (predicted ultimate load value) was carried out, and the preloading was carried out 2-3 times. During the preloading period, the number of test equipment indicators needs to be carefully checked, and the abnormal phenomena should be eliminated in time. After the preload is completed. Then, remove all loads and start the formal test. The test device is shown in Figure 5. Pressurized loading was used in the test. Each stage was kept for $10 \mathrm{~min}$, and the loading value of each stage was $0.2 N_{u}$ (predicted ultimate load value) $[30,31]$. The loading speed was $2 \mathrm{kN} / \mathrm{s}$. When the loading value reached $0.8 \mathrm{Nu}$, the loading value of each stage was $0.1 N_{u}$. When the last stage was loaded, the loading speed was $1 \mathrm{kN} / \mathrm{s}$. Until the ultimate load was reached and the pressure was kept, the loading was continuously and slowly until the specimen was destroyed. Among them, the strain data take the average value of 1 minute before the pressure was kept. Because the concrete column has $10 \mathrm{~mm}$ exposure in the upper and lower ends of the steel casing (Figure 5), the loading stops when the upper and lower loading plates contact the steel casing.

\section{Results and Discussion}

3.1. Main Results of the Test. The main test results are shown in Table 2. It can be seen from Table 2 that the ultimate load of strengthened columns increases differently with different prestress values. Compared with the contrast column, when the prestress value is $0 \mathrm{~N} / \mathrm{mm}^{2}$, the ultimate load of the strengthened column increases by $72.1 \%-92.4 \%$; when the 
TABLE 1: Details of specimens.

\begin{tabular}{lcccc}
\hline Methods & Number & Scheme & $\begin{array}{c}\sigma_{\theta} \\
(\mathrm{MPa})\end{array}$ & $\begin{array}{c}\text { Quantity } \\
\text { (pillar) }\end{array}$ \\
\hline $\begin{array}{l}\text { No } \\
\text { reinforcement }\end{array}$ & RC-1 & $\begin{array}{c}\text { No steel } \\
\text { casing }\end{array}$ & 0 & 5 \\
\hline \multirow{3}{*}{ Reinforcement } & RC-2-1 & Scheme 1 & 0 & 5 \\
& RC-2-2 & Scheme 2 & 24.68 & 5 \\
& RC-2-3 & Scheme 3 & 67.90 & 5 \\
\hline \multicolumn{7}{c}{ Total } & & 20 \\
\hline
\end{tabular}

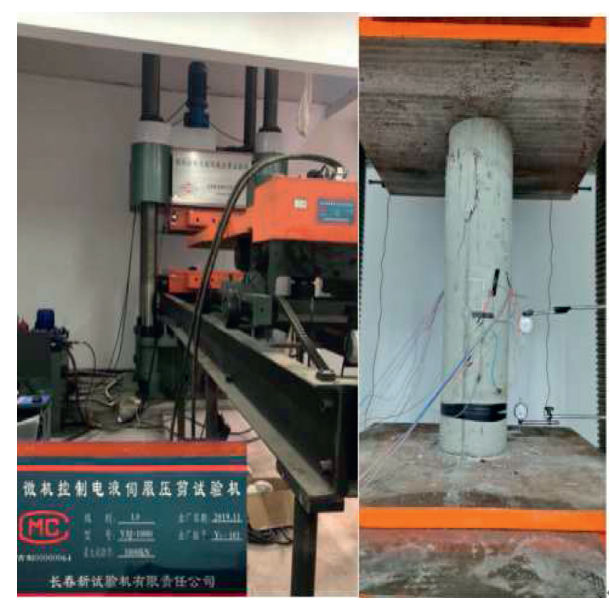

FIgURE 4: Testing machine.

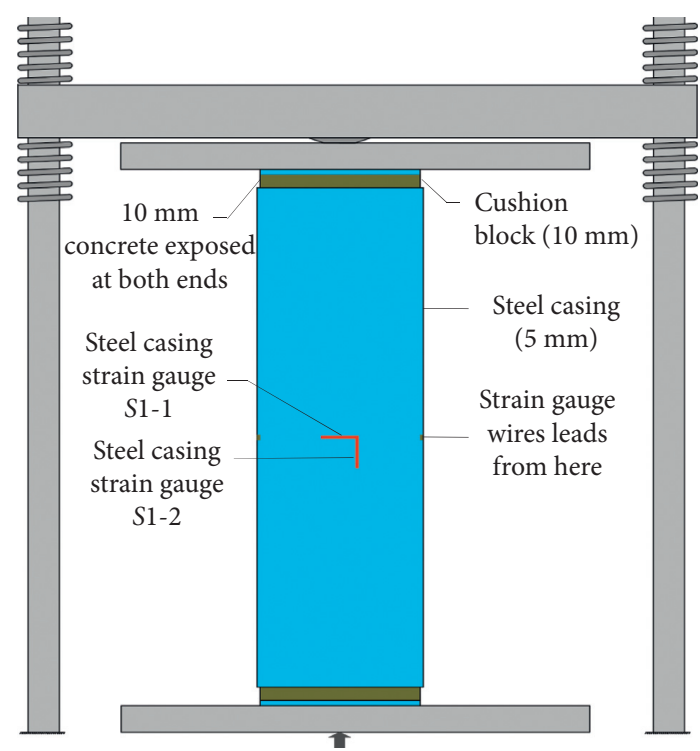

Figure 5: Diagram of specimen.

confining pressure of the semicircular steel plate on the concrete column is equivalent to that of the unreinforced column stirrup on core concrete, the ultimate load of the strengthened column increases by $95.0 \%-102.7 \%$; when the prestress value is equivalent to the prestress value required to make the bolt reach its tensile strength design value, the ultimate load of the strengthened column increases by $97.5 \%-109.9 \%$. It can be seen that, with the increase in the prestress value, the confinement effect of steel casing on concrete is more obvious, and the bearing capacity of concrete columns after reinforcement is slightly improved.

3.1.1. Phenomena. As shown in Figure 6, for RC-1, at the beginning of loading, two ends of the column due to stress concentration distribution crack. With the increase of load, because there is no restriction of steel casing, vertical cracks gradually appear in the surface of concrete cover. When the axial load reaches about $90 \%$ of its peak load, the vertical cracks continued to extend vertically, and the crack width increased. With a slight click, some cover concrete spalling. When the load reaches the maximum value, the head of the concrete column collapses in a large area, and the upper part of the specimen is bulging. Then, the bearing capacity decreases sharply. From the crack of the concrete column to the complete failure of the reinforced column, the whole process is relatively short, and the compression process shows the characteristics of brittle failure. For the three groups of concrete columns strengthened with steel casing, they have no obvious change at the initial stage of loading. When the load gradually increases, the appearance of steel casing has no obvious change, but its two vertical flanges have corrugated changes. Then, there was a crackling sound, which was due to the joint action of rib angle and bolt to make the vertical flange yield first. When the reinforced column reaches the ultimate bearing capacity, the weld position of the rib angle of the vertical flange is tear. Because the steel casing is restrained by the transverse flange during loading, the appearance of the steel casing still has no obvious change.

Figure 7 shows the internal failure mode diagram of the concrete cylinder after removing the steel plate. It can be seen that the failure of the ends of the column is more serious, which is due to the cushion plate that directly acts on the top of the concrete column during loading, and the end is not restrained by the steel casing. The ultimate compressive strain of concrete $\varepsilon_{c u}$ is 0.0033 ; from this, the ultimate displacement value is $3.3 \mathrm{~mm}$. Two ends of the reinforced column are compressed more than $10 \mathrm{~mm}$, indicating that the confined concrete in the concrete column has been compressed. However, due to the circumferential constraint of the steel casing, the concrete column can still withstand axial pressure. Therefore, the prestressed steel casing can effectively restrict the concrete column. After loading, the steel casing is closely connected with the surface of the concrete cylinder, and it is very difficult to separate them. This shows that the Poisson displacement or lateral displacement of the concrete in the steel casing is obvious, and the steel casing ensures the integrity of the specimen and the effectiveness of the pressure transfer.

3.1.2. Failure Patterns of Specimens. There are two typical failure modes of concrete column: (1)The top concrete is crushed and peeled off. (2)Due to the constraint effect of the steel casing on the core concrete, the whole shearing destruction of the concrete will not appear, and even the cracked concrete will be re-extrusion under the constraint of 
TABLE 2: Main results of the test.

\begin{tabular}{|c|c|c|c|c|}
\hline Nun & & $N_{u}(\mathrm{kN})$ & Increase rate $(\%)$ & Failure mode \\
\hline \multirow{5}{*}{$\mathrm{RC}-1$} & 1 & 1471.50 & - & \multirow{5}{*}{ Cover concrete spalling, concrete crushing, upper column drumming } \\
\hline & 2 & 1553.30 & - & \\
\hline & 3 & 1548.53 & - & \\
\hline & 4 & 1612.32 & - & \\
\hline & 5 & 1526.23 & - & \\
\hline \multirow{5}{*}{$\mathrm{RC}-2-1$} & 1 & 2654.89 & 72.1 & \multirow{5}{*}{ Concrete cracking, no obvious phenomenon in the steel casing } \\
\hline & 2 & 2910.25 & 88.7 & \\
\hline & 3 & 2967.48 & 92.4 & \\
\hline & 4 & 2938.08 & 90.5 & \\
\hline & 5 & 2781.00 & 80.3 & \\
\hline \multirow{5}{*}{$\mathrm{RC}-2-2$} & 1 & 3017.00 & 95.6 & \multirow{5}{*}{ Vertical flange weld cracking, concrete splitting } \\
\hline & 2 & 3008.29 & 95.0 & \\
\hline & 3 & 3026.02 & 96.2 & \\
\hline & 4 & 3110.64 & 101.7 & \\
\hline & 5 & 3125.31 & 102.7 & \\
\hline \multirow{5}{*}{$\mathrm{RC}-2-3$} & 1 & 3133.54 & 103.2 & \multirow{5}{*}{ Bolt fracture, steel casing failure } \\
\hline & 2 & 3146.81 & 104.0 & \\
\hline & 3 & 3046.87 & 97.5 & \\
\hline & 4 & 3237.70 & 109.9 & \\
\hline & 5 & 3304.70 & 114.3 & \\
\hline
\end{tabular}

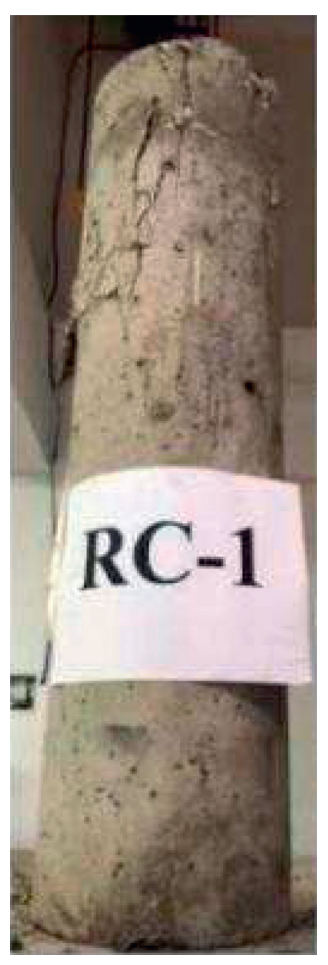

(a)

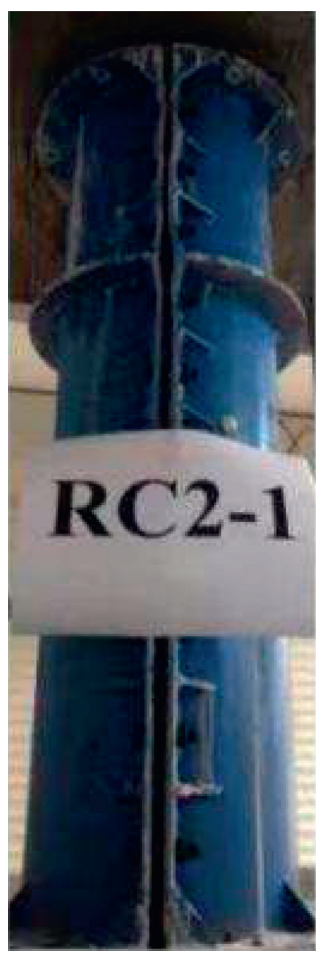

(b)

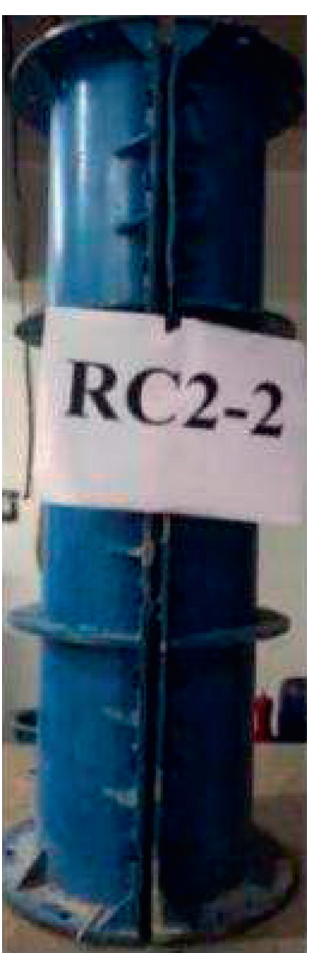

(c)

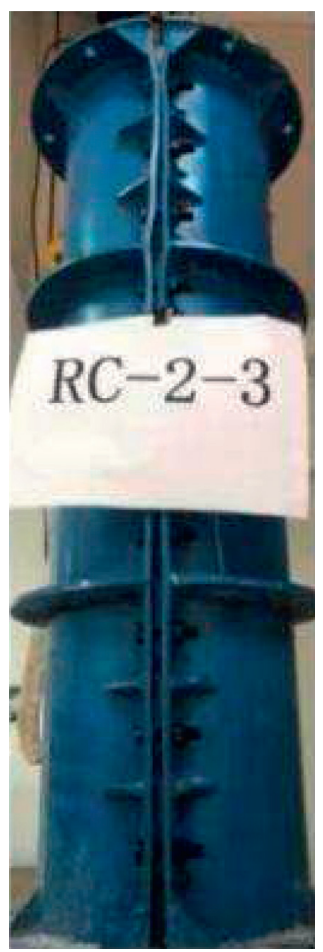

(d)

FIGURE 6: Failure modes of typical specimens.

the axial pressure and the steel casing. Due to the continuous occurrence of new corrugated bending of the vertical flange of the steel casing, cracks appear at the welds of the vertical flange, and the confining pressure is gradually weakened. On the premise of ensuring that no shear failure occurs, the reinforced column mainly occurs in two types of failure forms: the first type is axial compression failure; concrete columns in the compression zone are crushed and peeled off. The second type is the failure of the vertical flange of steel casing. From the cracking of reinforced columns under failure, two failure modes are ductile failure. Because the reinforced column has concrete spalling and clicking sound before failure, it shows that there are obvious signs before failure, and the failure form is reasonable. 


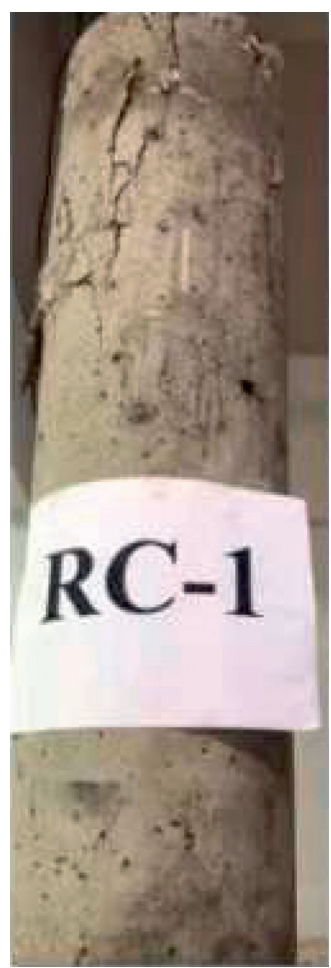

(a)

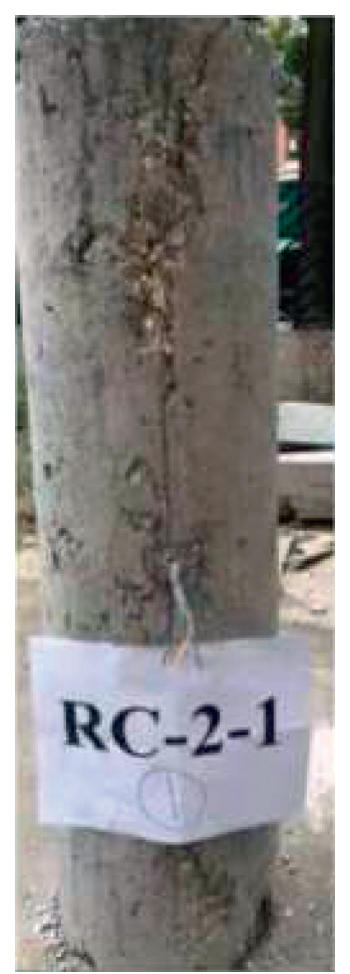

(b)

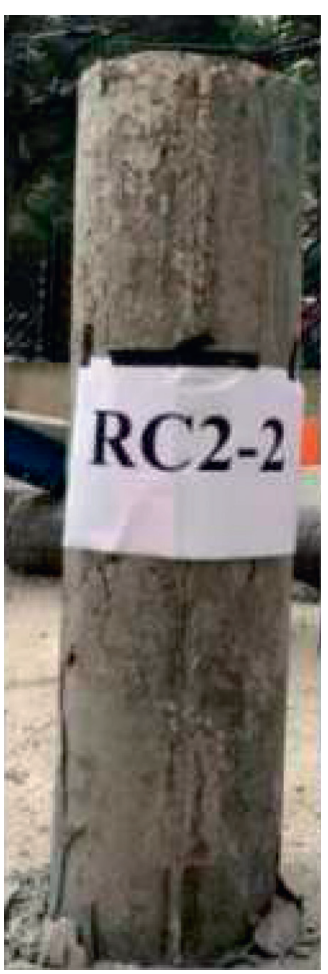

(c)

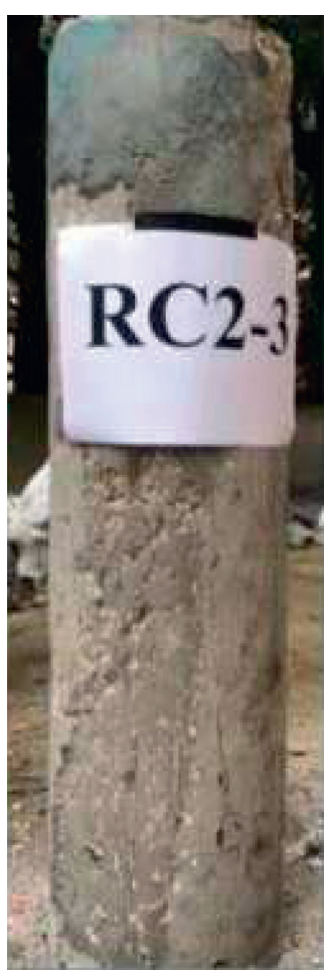

(d)

FIGURE 7: Internal failure mode of test column.

3.1.3. Load-Displacement Curve. Figure 8 shows the loaddisplacement curve of reinforced column. The curve can be divided into elastic section at the beginning of loading, inelastic section at $80 \%$ of ultimate load, and descending section after ultimate load. During the initial loading, all columns are in the elastic stage. Because fine stone concrete is poured between the steel casing and the concrete column to make them fit closely, the steel casing has a constraint effect on the core concrete. Therefore, with the increase of load, the greater the prestress value, the greater the slope of the strengthened column. As the load continues to increase, the constraint effect of steel casing on concrete becomes more obvious, and the bearing capacity of reinforced columns is also larger. Compared with the contrast column, the bearing capacities of RC2-1, RC2-2, and RC2-3 of the reinforced column were increased by $85 \%, 98 \%$, and $106 \%$, respectively. Because the steel casing has a strong constraint on concrete, the ultimate bearing capacity decreases slowly when it is destroyed, and for the specimens RC-1, RC2-1, $\mathrm{RC} 2-2$, and RC2-3, $\Delta_{\text {max }} / \Delta_{\text {elastic }}$ is $1.06,2.57,2.77,3.48$, respectively $\left(\Delta_{\max }\right.$ is the ultimate displacement, and $\Delta_{\text {elastic }}$ is the elastic displacement). It shows that the ductility of the new concrete structure increases with the increase of steel casing prestress.

3.1.4. Load-Material Strain Curve. Figure 9 shows the loadstrain curve of the concrete and steel casing. In the early stage of loading, the load-strain is linear, which indicates that the reinforced column is in the elastic stage. The strain

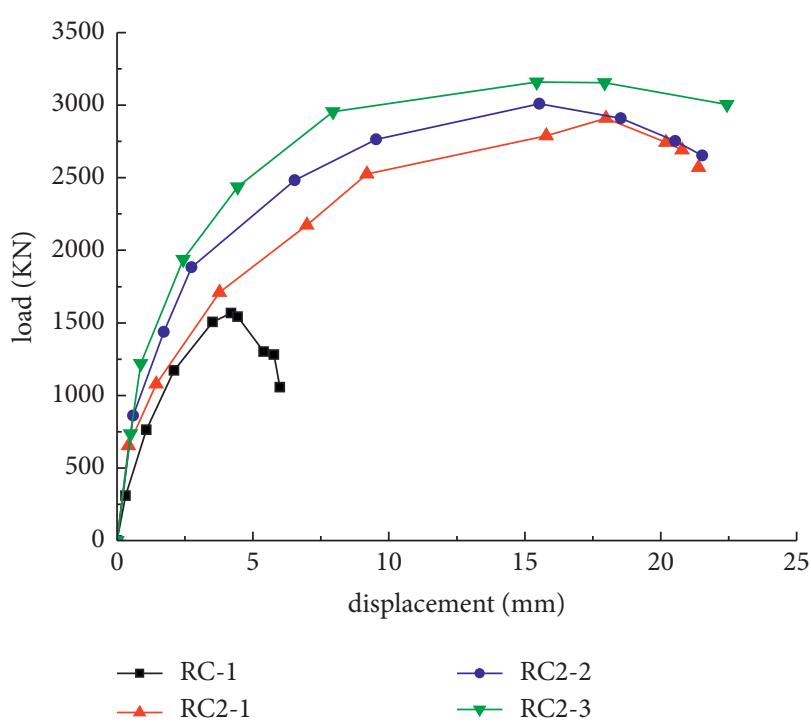

FIgURE 8: Load-displacement curves.

of concrete and steel casing increases proportionally with the increase of load. When the load increases to $50 \%$, the column cracks and works with cracks. With the increase of load, the strain of concrete increases and the transverse strain of steel casing also increases. The longitudinal strain of steel casing increases mainly due to the increase of transverse strain of steel casing. When the load is close to $N_{u}$, the slope of the curve continues to decrease, the stiffness of the specimen 


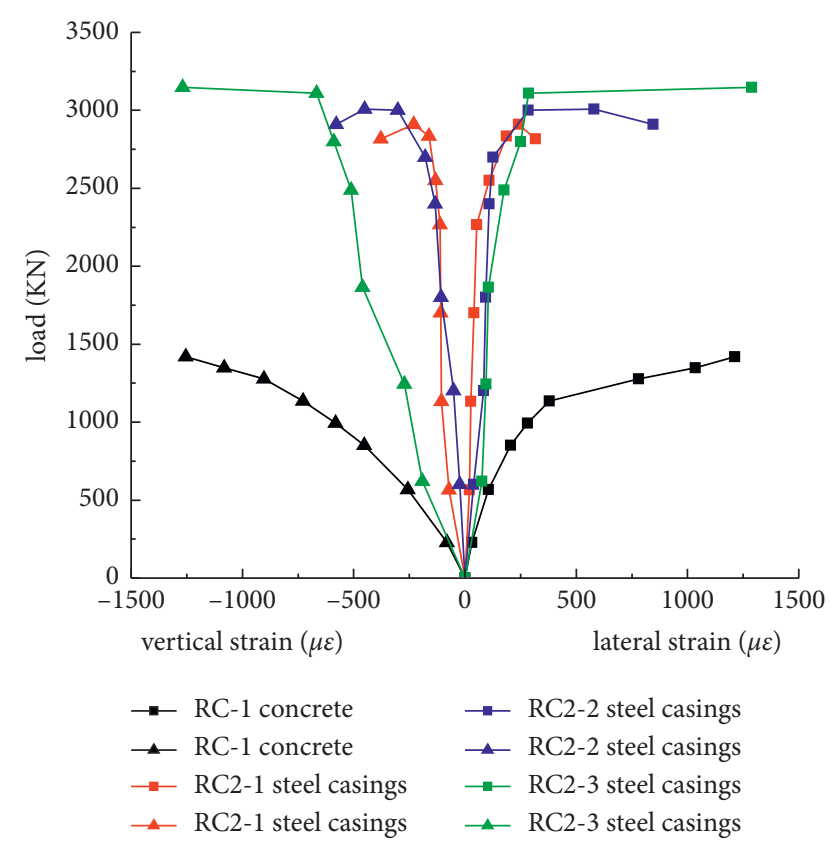

FIGURE 9: Load-strain curves of concrete and steel casings.

decreases, and the reinforced column is destroyed. When specimens RC2-1, RC2-2, and RC2-3 reach the ultimate load, the transverse strains of steel casing are 241, 580, and $1288 \mu_{\varepsilon}$, and the longitudinal strains are 231, 450, and 1268 $\mu_{\varepsilon}$, respectively.

Figure 10 shows the load-strain curve of the steel bar of the reinforced column. With the increase in the steel casing prestress value, the constraint effect on the concrete column is stronger, and the increase of the peak strain of the steel bar (the strain corresponding to the ultimate load) is greater. When the specimens RC-1, RC2-1, RC2-2, and RC2-3 reach the ultimate load, the stirrup strains are 1120, 650, 584, and $3025 \mu_{\varepsilon}$, and the longitudinal reinforcement strains are 1767, 1284, 1675, and $2292 \mu_{\varepsilon}$, respectively. Comparing the reinforced columns RC2-1, RC2-2, and RC2-3, it is known that the prestressed semicircular steel plate reinforcement can improve the ultimate strain of concrete, and the concrete strain is related to the size of reinforcement prestress. The greater the prestress, the greater the ultimate strain of the reinforcement column. And the strain growth rate of the reinforced column is accelerated after the peak load, indicating that the prestressed semicircular steel plate reinforcement gives full play to the material properties of steel and concrete. It can be seen from the figure that the steel strain of the contrast column RC-1 decreases directly after reaching the ultimate load. Due to the transverse constraint force provided by the prestressed semicircular steel plate, the steel strain of the reinforced column decreased slowly after reaching the ultimate load.

\subsection{Finite Element Analysis}

3.2.1. Finite Element Modeling. In this article, ABAQUS software is used for finite element analysis. The steel skeleton and concrete are contacted by the embedded

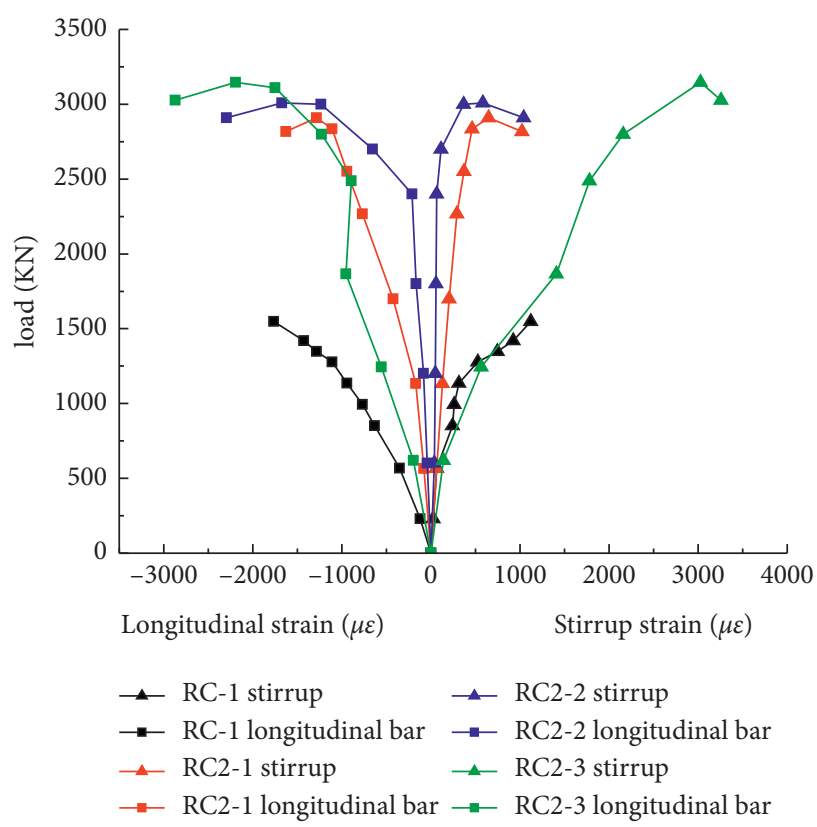

Figure 10: Load-strain curve of steel bar.

region without considering the influence of bond-slip, and it is assumed to be coordinated deformation. Although the steel casing and concrete column surface will produce relative slip in the actual test, many research results show that this relative slip has little effect on the constraint ability, so this article assumes that they are ideally connected and use tie contact. In the existing research field, the application method of steel casing prestress is still relatively rare. High strength bolts are used to apply prestress in the test, but, in the simulation, the equivalent substitution method is used to control prestress, and the prestress is equivalent to the pressure generated around the concrete column; that is, the contact element between the steel casing and the concrete transfers the interface pressure $p$, and the pressure perpendicular to the contact surface can be completely transferred between the interfaces. Only normal contact is considered between the cushion plate and the top surface of the concrete. Among them, the steel casing and two ends of the cushion plate are simulated by shell element S4R, and the concrete is simulated by three-dimensional solid element C3D8R.

The constitutive model of the concrete column strengthened with prestressed steel casing is similar to that of the concrete-filled steel tubular column. Therefore, the constitutive model of concrete in this simulation adopts the compression constitutive model of the concrete-filled steel tubular column in Liu Wei's study on the working mechanism of the concrete-filled steel tubular column under local compression [32]. The loading method adopts the vertical displacement loading of the upper part of the model. It is assumed that the lower part of the model is completely fixed, and the upper part constrains two translational and rotational degrees of freedom. The finite element model is shown in Figure 11. 


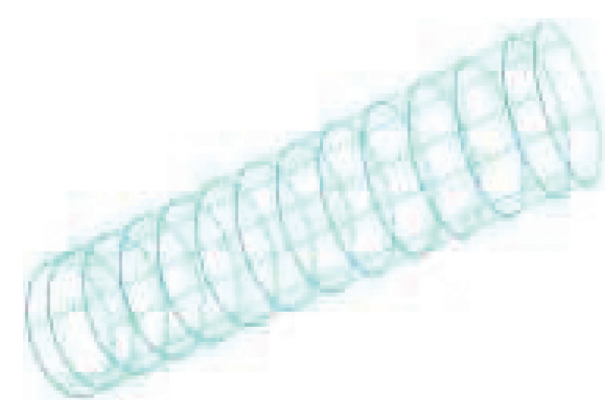

(a)

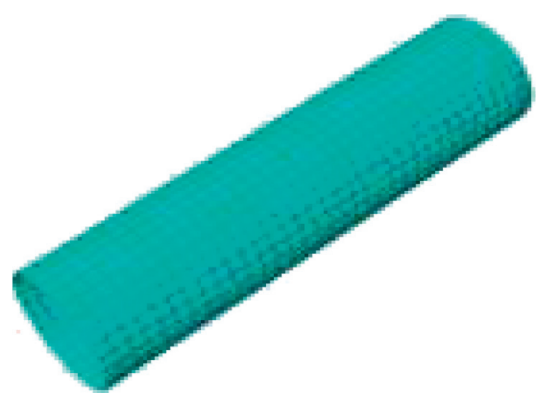

(b)

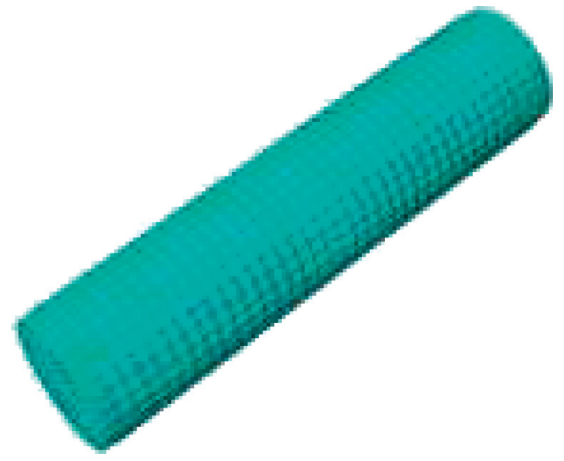

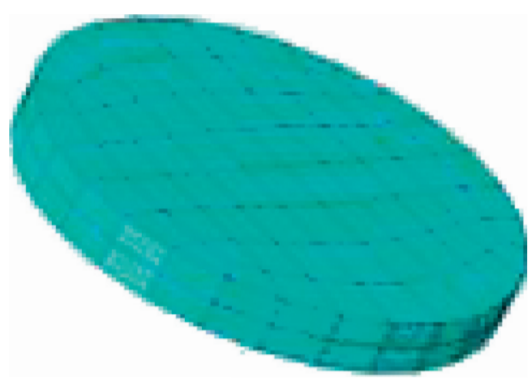

(c)

(d)

Figure 11: Model mesh subdivision. (a) Steel frame. (b) Steel casings. (c) Cushion block. (d) The whole specimen.

3.2.2. Results of Finite Element. Figure 12 shows the stress distribution nephogram of the steel casing when the reinforced column reaches the ultimate load when the prestress of the steel casing is $0 \mathrm{~N} / \mathrm{mm}^{2}, 24.68 \mathrm{~N} / \mathrm{mm}^{2}$, and $67.90 \mathrm{~N} / \mathrm{mm}^{2}$, respectively. It can be seen from the figure that with the increase in the prestress value, the coverage of the maximum stress of the steel casing increases and is distributed in the middle area of the reinforced column. And with the increase in the prestress value, the compressive stress value increases, it shows that the steel casing has a good restraint effect, and the restraint effect is also obvious. There is a certain error between the finite element simulation and the test results; the main reason for the error is that there is a deviation between the application mode of prestress of reinforced columns and the actual situation during modeling. Moreover, the contact between steel casing and concrete is also complete contact in the ideal state, which is difficult to achieve in the actual project.

Figure 13 shows the load-displacement curve of the specimen obtained by the test and the finite element method. The real line represents the finite element value. The imaginary line represents the experimental value. It can be seen that the calculation results of the finite element model are consistent with the test results. The finite element analysis tends to be idealized. Therefore, the finite element analysis results are better than the test results. The comparison of specimen bearing capacity is shown in Table 3, $N_{\text {FEM }} / \bar{N}_{\text {EXP }}$ mean value is 1.026 , and the standard deviation is 0.012 , indicating that the finite element model established in this article can better simulate the stress characteristics of reinforced concrete columns strengthened with prestressed steel casing.

\section{Calculation of Axial Compression Bearing Capacity}

The prestressed steel casing reinforcement method studied in this article is a new reinforcement method. By prestressing the steel casing, the steel casing and the column needed to be strengthened are connected into a whole, so that they work together, thus significantly improving the bearing capacity of concrete columns.

Referring to the research results of Si et al. [33] in the axial compression test of damaged reinforced concrete columns strengthened with prestressed steel wires, after reinforcement, the bearing capacity of the reinforced column is composed of longitudinal reinforcement and confined concrete, and thus, the calculation formula of the bearing capacity of the reinforced column with prestressed steel wires is proposed:

$$
\begin{array}{r}
N_{u}=\phi \cdot f_{c, c} A_{c}+f_{y}^{\prime} A_{s}^{\prime}, \\
f_{c, c}=b \cdot f_{c},
\end{array}
$$

where $N_{u}$ is the ultimate bearing capacity of the composite strengthened member, $\mathrm{kN} ; f_{c, c}$ is the axial compressive strength of confined concrete, $\mathrm{MPa} ; b$ is the prestressed winding improvement coefficient; $f_{c}$ is the axial compressive strength of unconstrained concrete, $\mathrm{MPa} ; A$ is the damage coefficient; $A_{c}$ is the section area of compressive concrete, $\mathrm{mm}^{2} ; f_{y}$ is the longitudinal reinforcement compressive 


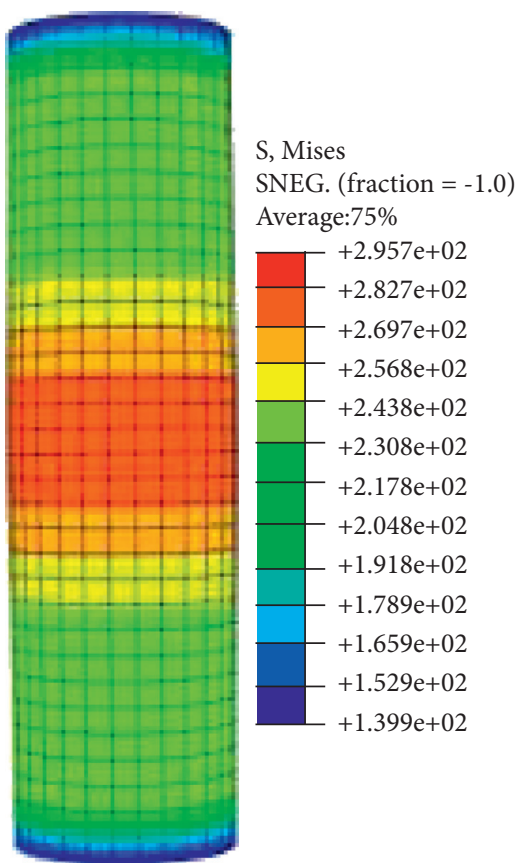

(a)

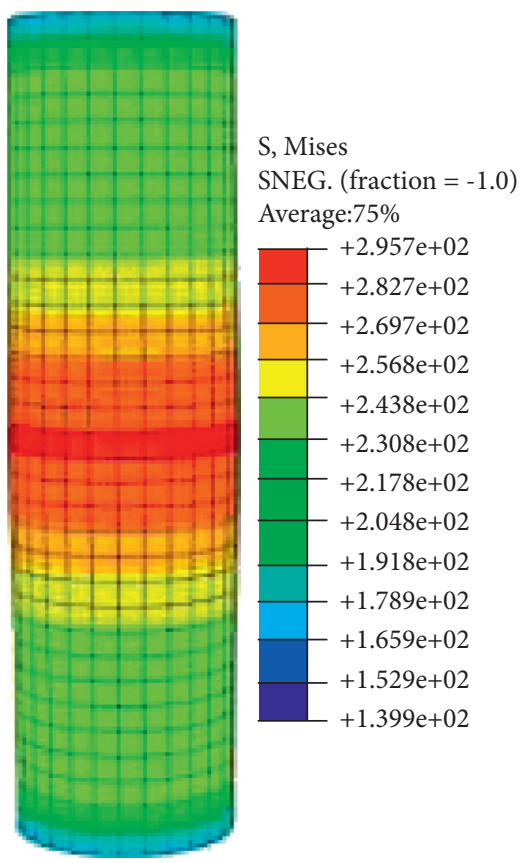

(b)

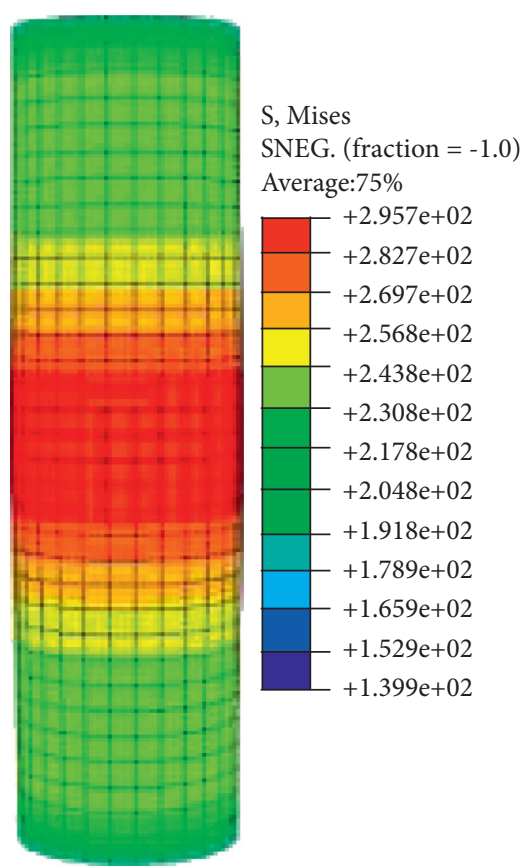

(c)

FIgURe 12: Strain cloud picture (MPa). (a) RC2-1. (b) RC2-2. (c) RC2-3.

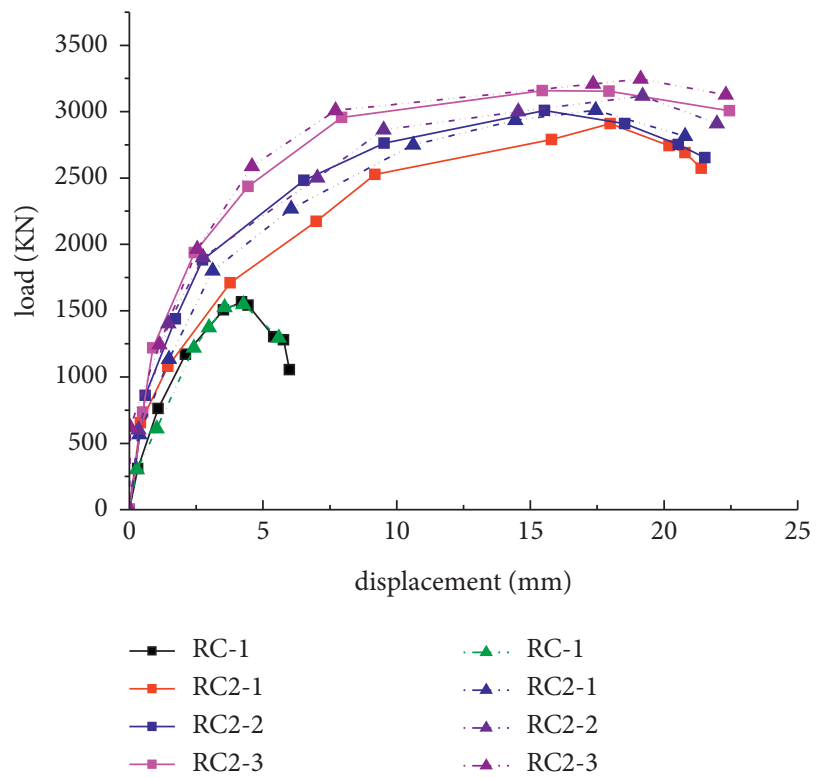

FIGURE 13: Load-displacement curve.

strength design value, $\mathrm{MPa}$; and $A_{s}$ is the longitudinal section area, $\mathrm{mm}^{2}$.

Based on the derivation of Si Jianhui's calculation formula for the bearing capacity of reinforced members, it can be seen from Figure 5 that there are $10 \mathrm{~mm}$ left at the upper and lower ends of the concrete column without the constraint of steel plate. Therefore, the steel casing does not provide axial bearing capacity, but only provides one circumferential constraint force for the concrete column in this experiment. It can be seen that the increase in the bearing capacity of concrete columns strengthened with prestressed steel casing is mainly caused by the increase in the bearing capacity of concrete after being constrained [30, 34-36]. Due to the different prestress value, the ultimate compressive strain of confined concrete is different, and the strain of the steel bar is also different, so it is necessary to set up a composite reinforcement improvement coefficient. Since the specimens used in the test are all not under pressure before the test, the damage coefficient $A$ can be taken as 1 . Then calculation formula of the bearing capacity of concrete 
TABLE 3: Comparison of experimental and calculated values.

\begin{tabular}{|c|c|c|c|c|c|c|c|c|c|}
\hline \multirow{2}{*}{ Number } & \multicolumn{6}{|c|}{$N_{\text {EXP }}(\mathrm{kN})$} & \multirow{2}{*}{$N_{\text {FEM }}(\mathrm{kN})$} & \multicolumn{2}{|c|}{$N_{c}(\mathrm{kN})$} \\
\hline & 1 & 2 & 3 & 4 & 5 & Average & & Formula (7) & Error (\%) \\
\hline RC-1 & 1471.50 & 1553.30 & 1548.53 & 1612.32 & 1526.23 & 1542.38 & 1548.53 & 1419.67 & 8 \\
\hline RC-2-1 & 2654.89 & 2910.25 & 2967.48 & 2938.08 & 2781.00 & 2850.34 & 3010.25 & 2833.62 & 0.6 \\
\hline RC-2-2 & 3017.00 & 3008.29 & 3026.02 & 3110.64 & 3125.31 & 3057.45 & 3118.29 & 2921.90 & 4.4 \\
\hline RC-2-3 & 3133.54 & 3146.81 & 3046.87 & 3237.70 & 3304.70 & 3173.92 & 3246.81 & 3083.75 & 2.8 \\
\hline
\end{tabular}

Note. $N_{\text {EXP }}$ is the test bearing capacity. $N_{\text {FEM }}$ is the bearing capacity of finite element analysis. $N_{C}$ is the calculated bearing capacity.

columns strengthened with prestressed steel casing can be simplified as follows:

$$
N_{u}=b f_{c} A_{c}+f_{y}^{\prime} A_{s}^{\prime}
$$

where $b$ is the prestress increase coefficient, which is obtained by fitting from the relationship between prestress $f$ and bearing capacity of steel casing by Origin software, $b=0.005 f+3.40$.

The calculated results of formula (7) are compared with the experimental data and summarized in Table 3. It can be seen from Table 3 that the calculation results of formula (7) are in good agreement with the measured values.

\section{Conclusions}

In this article, the prestressed steel casing reinforcement method was proposed. Through the axial compression test and numerical simulation of 20 columns, the following preliminary conclusions can be drawn:

(1) Compared with the original column, the ultimate bearing capacity of reinforced concrete columns strengthened with prestressed steel casing is increased by $72.1 \%-109.9 \%$, and the ductility is also greatly improved.

(2) The calculation formula of the axial compression bearing capacity of reinforced concrete columns strengthened with prestressed steel casing provided in this article has good applicability. Compared with the experimental values, the theoretical calculation formula has sufficient accuracy.

(3) The reinforcement effect of the prestressed steel casing reinforcement method is obvious, which is suitable for rapid repair and reinforcement of concrete columns that need to greatly improve the bearing capacity in a short time.

(4) ABAQUS software was used to model and analyze the test process. The results show that the finite element results are in good agreement with the test results. The comparative analysis results of models under different prestress levels show that when the prestress of steel casing is $0 \mathrm{~N} / \mathrm{mm}^{2}, 24.68 \mathrm{~N} / \mathrm{mm}^{2}$, and $67.90 \mathrm{~N} / \mathrm{mm}^{2}$, the simulated bearing capacity increases by $94 \%, 101 \%$, and $110 \%$, respectively.

\section{Data Availability}

All data used to support the study are included within the article.

\section{Consent}

Not applicable.

\section{Conflicts of Interest}

The authors declare that they have no conflicts of interest.

\section{Authors' Contributions}

Z.R was responsible for methodology; Y.S was responsible for software and performed investigation; X.Z validated the data and prepared the original draft; Z.R and Y.S reviewed and edited the manuscript and helped with funding acquisition; Z.R and X.Z contributed to the project administration. All authors have read and agreed to the published version of the manuscript.

\section{Acknowledgments}

This research was funded by the Fundamental Research Funds for the Key Project of Research and Development Plan of Hunan Province 2020SK2109, National Natural Science Foundation of Hunan Province 2021JJ50106, National Natural Science Foundation of China 52104106, and Basic Research Program of Xuzhou (KC21017).

\section{References}

[1] Z. Ren, X. Zeng, and J. Sun, "Using two-way prestressed semicircular steel plate for construction of reinforced concrete cylinder column," Complexity, vol. 2018, Article ID 1481837, 10 pages, 2018.

[2] Y. Tang, W. Feng, Z. Chen, Y. Nong, S. Guan, and J. Sun, "Fracture behavior of a sustainable material: recycled concrete with waste crumb rubber subjected to elevated temperatures," Journal of Cleaner Production, vol. 318, Article ID 128553, 2021.

[3] Z. Ren, X. Zeng, J. Sun, and J. Wang, "Fracture properties of wide-notch concrete beams strengthened with near-surface mounted CFRP rebar," KSCE Journal of Civil Engineering, vol. 23, no. 11, pp. 4735-4746, 2019. 
[4] B. Zhou, M. Zhang, L. Wang, and G. Ma, "Experimental study on mechanical property and microstructure of cement mortar reinforced with elaborately recycled GFRP fiber," Cement and Concrete Composites, vol. 117, Article ID 103908, 2021.

[5] X. Tan, Z. Hu, C. Chen, and M. Zhao, "3D DEM-FDM coupled analysis of the behavior of an isolated geogridencased stone column under axial loading," Journal of Geotechnical and Geoenvironmental Engineering, vol. 147, no. 6, Article ID 04021028, 2021.

[6] L. Hu and P. Feng, "Prestressed CFRP-reinforced steel columns under axial and eccentric compression," Composite Structures, vol. 268, Article ID 113940, 2021.

[7] L. Hu, P. Feng, and X. L. Zhao, "Fatigue design of CFRP strengthened steel members," Thin-Walled Structures, vol. 119, pp. 482-498, 2017.

[8] J. Zhang, Y. Sun, G. Li, Y. Wang, J. Sun, and J. Li, "Machinelearning-assisted shear strength prediction of reinforced concrete beams with and without stirrups," Engineering with Computers, vol. 36, pp. 1-15, 2020.

[9] W. Yayong, "Fire Resistance Test of RC Beam Retrofitted with Cover of High Strength Steel Mesh and Polymetric Motar," Building Structure, vol. 37, no. 1, pp. 112-113, 2007.

[10] Y. Sun, G. Li, and J. Zhang, "Developing hybrid machine learning models for estimating the unconfined compressive strength of jet grouting composite: a comparative study," Applied Sciences, vol. 10, no. 5, 2020.

[11] W. Ge, W. Song, A. F. Ashour, W. Lu, and D. Cao, "Flexural performance of FRP/steel hybrid reinforced engineered cementitious composite beams," Journal of Building Engineering, vol. 31, Article ID 101329, 2020.

[12] Y. Sun, G. Li, and J. Zhang, "Investigation on jet grouting support strategy for controlling time-dependent deformation in the roadway," Energy Science \& Engineering, vol. 8, no. 6, pp. 2151-2158, 2020.

[13] Y. Sun, R. Bi, Q. Chang et al., "Stability analysis of roadway groups under multi-mining disturbances," Applied Sciences, vol. 11, no. 17, 2021.

[14] Y. Yong, L. Hui, and C. Wei, "Experimental study on seismic behavior of reinforced concrete frame structure retrofitted by prestressed steel strips," Engineering Mechanics, vol. 34, no. 10, pp. 53-60, 2017.

[15] Y. Sun, L. Guichen, Z. Junfei, S. Junbo, and X. Jiahui, "Development of an ensemble intelligent model for assessing the strength of cemented paste backfill," Advances in Civil Engineering, vol. 2020, Article ID 1643529, 6 pages, 2020.

[16] C. X. C. C. Yun-peng, "On reliable analysis of section-enlarging reinforcing method in strengthening frame structure," Shanxi Architecture, vol. 2, 2010.

[17] J. Sun, Y. Huang, F. Aslani, and G. Ma, "Electromagnetic wave absorbing performance of $3 \mathrm{D}$ printed wave-shape copper solid cementitious element," Cement and Concrete Composites, vol. 114, Article ID 103789, 2020.

[18] C. J. X. Jin, "Ultimate strength of reinforced concrete columns strengthened by circular steel jacketing," Journal of South China University of Technology, vol. 35, no. 10, pp. 78-83, 2007.

[19] Y. Sun, G. Li, J. Zhang, J. Sun, J. Huang, and R. Taherdangkoo, "New insights of grouting in coal mass: from small-scale experiments to microstructures," Sustainability, vol. 13, no. 16, 2021.

[20] L. Hu, Y. Wang, P. Feng, H. Wang, and H. Qiang, "Debonding development in cracked steel plates strengthened by CFRP laminates under fatigue loading: experimental and boundary element method analysis," Thin-Walled Structures, vol. 166, Article ID 108038, 2021.

[21] L. L. Hu, X. L. Zhao, and P. Feng, "Fatigue behavior of cracked high-strength steel plates strengthened by CFRP sheets," Journal of Composites for Construction, vol. 20, no. 6, Article ID 04016043, 2016.

[22] G. Ma, J. Sun, F. Aslani, Y. Huang, and F. Jiao, "Review on electromagnetic wave absorbing capacity improvement of cementitious material," Construction and Building Materials, vol. 262, Article ID 120907, 2020.

[23] J. Sun, Y. Huang, F. Aslani, X. Wang, and G. Ma, "Mechanical enhancement for EMW-absorbing cementitious material using 3D concrete printing," Journal of Building Engineering, vol. 41, Article ID 102763, 2021.

[24] J. Sun, "Fresh and mechanical behaviour of developed fibrereinforced lightweight engineered cementitious composites for $3 \mathrm{D}$ concrete printing containing hollow glass microspheres," Ceramics International, vol. 47, no. 19, pp. 2710727121, 2021.

[25] Standard for Test Method of Mechanical Properties on Ordinary concrete, Ministry of Construction of the People's Republic of China, Beijing, China, 2002.

[26] W. Ge, Y. Wang, A. Ashour, W. Lu, and D. Cao, "Flexural performance of concrete beams reinforced with steel-FRP composite bars," Archives of Civil and Mechanical Engineering, vol. 20, pp. 1-17, 2020.

[27] W. Ge, K. Chen, Z. Guan, A. Ashour, W. Lu, and D. Cao, "Eccentric compression behaviour of concrete columns reinforced with steel-FRP composite bars," Engineering Structures, vol. 238, Article ID 112240, 2021.

[28] J. Sun, F. Aslani, J. Wei, and X. Wang, "Electromagnetic absorption of copper fiber oriented composite using 3D printing," Construction and Building Materials, vol. 300, Article ID 124026, 2021.

[29] "Standard test methods for concrete structures, ," 2012.

[30] J. Li, Q. Qin, J. Sun, Y. Ma, and L. Qia, "Mechanical and conductive performance of electrically conductive cementitious composite using graphite, steel slag, and ggbs," Structural Concrete, Wiley, NJ, USA, 2020.

[31] J. Sun, Y. Wang, S. Liu et al., "Mechanical, chemical and hydrothermal activation for waste glass reinforced cement," Construction and Building Materials, vol. 301, Article ID 124361, 2021.

[32] W. Liu, Research on Mechanism of concrete-filled Steel Tubes Subjected to Local Compression, pp. 64-65, Fuzhou University, Fuzhou, China, 2005.

[33] J. Si, L. Wu, and W. Guo, “Axial compression of reinforced concrete columns strengthened by composite of prestressed plastic-steel strip and angle steel: an experimental study," Structural Concrete, Wiley, NJ, USA, 2021.

[34] W. Ma, X. Wang, J. Wang, J. Sun, and X. Xiang, "Generative design in building information modelling (BIM): approaches and requirements," Sensors, vol. 21, no. 16, 2021.

[35] J. Sun, Y. Wang, X. Yao et al., "Machine-Learning-Aided prediction of flexural strength and ASR expansion for waste glass cementitious composite," Applied Sciences, vol. 11, no. 15, p. 6686, 2021.

[36] J. Sun, Y. Ma, J. Li, J. Zhang, Z. Ren, and X. Wang, "Machine learning-aided design and prediction of cementitious composites containing graphite and slag powder," Journal of Building Engineering, vol. 43, Article ID 102544, 2021. 